\title{
Surgical Scalpel vs Laser: A Comparative Clinical Study in Intra Oral Incisional Biopsy
}

\section{ISSN: 2637-7764}

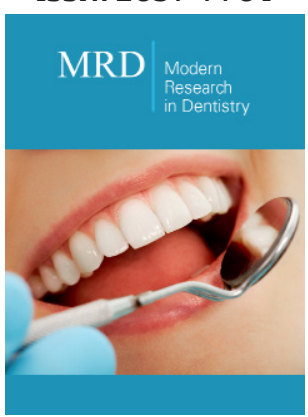

*Corresponding author: Jayesh, Oral and Maxillofacial Surgery, Senior Lecturer, Department of Oral and Maxillofacial Surgery, Hazaribagh College of Dental Sciences, Jharkhand, India

Submission: 海 November 23, 2020

Published: 笽February 22, 2021

Volume 6 - Issue 1

How to cite this article: Jayesh Sibgatullah, Aklanta Kumar Gogoi, Vidhya Ningrajappa, Ningombam Gitson Meitei, et al. Surgical Scalpel vs Laser: A Comparative Clinical Study in Intra Oral Incisional Biopsy. Mod Res Dent. 6(1). MRD. 000630. 2021.

DOI: 10.31031/MRD.2021.06.000630

Copyright@ Jayesh, This article is distributed under the terms of the Creative Commons Attribution 4.0 International License, which permits unrestricted use and redistribution provided that the original author and source are credited.
Jayesh $^{1 *}$,Sibgatullah ${ }^{2}$,Aklanta Kumar Gogoi ${ }^{3}$, Vidhya Ningrajappa ${ }^{3}$, Ningombam Gitson Meitei ${ }^{4}$ and Malvika N Hasrajani ${ }^{3}$

${ }^{1}$ Oral and Maxillofacial Surgery, Senior Lecturer, Department of Oral and Maxillofacial Surgery, Hazaribagh College of Dental Sciences, Jharkhand, India

${ }^{2}$ Oral and Maxillofacial Surgery, Director, MK Advanced Dental Hospital, Ranchi, Jharkhand, India

${ }^{3}$ MDS-Oral and Maxillofacial Surgery

${ }^{4}$ Oral and Maxillofacial Surgery, Shijacity Dental Hospital

Bangalore

\section{Abstract}

Background and objectives: To compare diode laser incision with traditional blade incision for soft tissue incisional biopsy in terms of Hemostasis, Local anesthetic required, Duration of procedure and Post-operative pain.

Methods: The following study was conducted in department of oral and maxillofacial surgery, Oxford Dental College, Bengaluru from November 2015 to August 2017. Sixty patients were enrolled in the study based on the indication for incisional biopsy and were randomly divided into two groups of thirty each. The biopsy was carried out using a. B.P handle and 15 no. blade and Diode laser at $980 \mathrm{~nm}$ wavelength and 3 watts power in contact mode with $200 \mathrm{~nm}$ activated fiber. The biopsies were conducted under infiltration of local anesthesia (2\% lignocaine hydrochloride with 1:200,000 adrenaline). The biopsies were marked with laser or incisional before being sent to the oral pathologist.

Result: In comparison between two groups: the amount of local anesthesia needed in laser group was (mean $0.91+/-0.44)$ compared to scalpel group $(2.97+/-0.76 \mathrm{ml})$. The loss of blood (as calculated by subtracting the initial weight of gauge from final weight) in the laser group was $0.94+/-0.34 \mathrm{mg}$ when compared to scalpel group which was $8.79+/-0.88 \mathrm{mg}$ meaning the bleeding was less in laser group. The pain also was less in the laser group when compared to scalpel group both on day one and day three. The duration of the procedure was almost similar.

Interpretation \& Conclusion: The study showed that the Diode laser is a good alternative for soft tissue incisional biopsies with respect to scalpel as it has less bleeding, less post-operative pain and not much difference in total time for the procedure. With precautions laser biopsy can yield as good a specimen as a scalpel biopsy and in a setting that is comfortable to patient.

Keywords: Biopsy; Diode lasers; Incision; Surgical scalpel; Hemostasis; Pain

\section{Introduction}

Biopsy is defined as "the removal of tissue from the living organism for the purpose of microscopic examination and diagnosis" [1]. By using this technique, the histologic characteristics of the lesion are determined, it is differentiated from other lesions and its extent is recognized, based on which a treatment plan can be prepared [2].

In dentistry three methods are used to cut tissues. They are surgical scalpel, electrocautery and lasers. All three are proven methods for cutting of tissues with each having different characteristics regarding of hemostasis, healing time, cost of instruments, width of the cut, anesthetic requirement and disagreeable characteristics, such as smoke production, the odor of burning flesh and undesirable taste. Of the three lasers and surgical scalpel are most commonly used in dental soft tissue procedures under local anesthesia [3].

The word laser is acronym for Light Amplification by Stimulated Emission of Radiation. Laser as a device is capable of mobilizing intense heat and power when focused on a close range and it is used as a tool in surgical procedures, diagnosis and physiological studies [4]. 
Lasers are minimally invasive when compared to surgical scalpel, aids in hemostasis which leads to improved visibility during a surgical procedure, reduce bacterial load, help in wound healing and produce other photo biomodulation effects which can reduce pain [5].

\section{Aims and Objective}

The study was conducted to compare diode laser incision with Surgical scalpel incision for soft tissue incisional biopsy for the following:
a) Hemostasis
b) Amount of Local anesthetic required
c) Duration of procedure
d) Post-operative pain

\section{Methodology}

An institutional study was conducted in which 60 adult patients (ASA class I and class II) requiring incisional biopsy were selected. After a detailed case history recording which included extra-oral and intra-oral examination and inspection of the lesion patients were taken for incisional biopsy under local anesthesia.

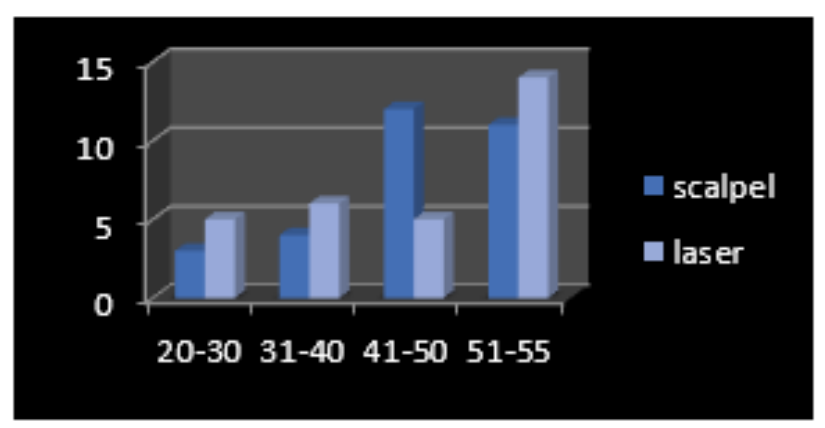

Graph 1: Age distribution.

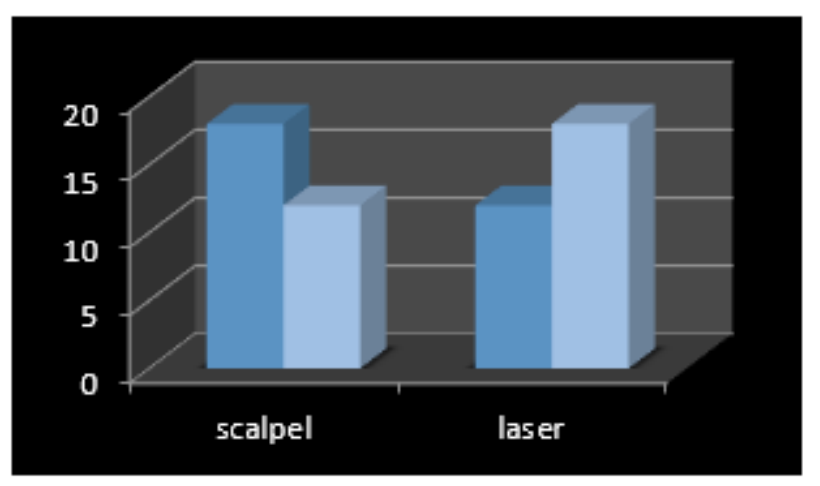

Graph 2: Gender distribution.

Patients were randomly divided into two groups of 30 patients each with one group undergoing incisional biopsy with Diode laser and the other group with surgical scalpel. Laser group had
12 males and 18 females while in the scalpel group there were 18 males and 12 females. The mean age of patients included in the laser group was $44.2+/-10.4$ and scalpel group were $45+/-8.8 y r s$ (Graph $1 \& 2$ ). Patients were evaluated for hemostasis (by weighing the gauze), local anesthetic required, duration of surgery and postoperative pain (visual analogue scale) was measured on $1^{\text {st }}$ and $3^{\text {rd }}$ post-operative day (Table 1) [3]. Before starting the procedure, the patients were informed about it and informed consent taken in patients own vernacular language. Patient were placed on a dental chair. Site of the lesion was identified, and a thorough betadine scrubbing was done intraorally and extra orally using surgical scrub. Local anesthesia (2\% Lignocaine Hydrochloride with $1: 200,000$ Adrenaline) was infiltrated near the site of lesion using a $2.5 \mathrm{ml}$ sterile disposable syringe.

A stopwatch was used to measure the time of the procedure. It was started once the local anesthesia was administered and stopped when hemostasis was achieved, and patient was ready to be discharged. Local anesthesia was locally administered about $3-4 \mathrm{~mm}$ away from the site of the lesion. Additional anesthesia was administered based on patient comfort level to pain. The total anesthesia given was recorded. The specimen was fixed in a $10 \%$ buffered solution at least 20 times the volume [6]. Preweighed sterile dry gauge was used to control bleeding during the procedures. The blood-soaked gauge was then measured post operatively and the change in weigh was recorded to measure the blood loss during the procedure. Post-operative suturing was done with 3-0 braided black silk sutures if required. Patient was then discharged once hemostasis had been achieved with post-operative instructions and medications given. Patient was recalled next day and on third post-operative day for Recording the pain recorded by VAS (visual analog scale).

\section{Procedure}

\section{Scalpel group}

An inferior margin incision was given first to prevent obscuring the entire field with blood. Normal tissue extending beyond the lesion margins were included in the biopsy. Sufficient depth was obtained following which the tissue was held with a non-toothed Adson's tissue holding forceps and the base was released with a surgical scalpel following which the area was sutured to achieve hemostasis. Patient was discharged when hemostasis had been achieved (Figure 1).

\section{Laser group}

Laser safety precautions, eye wear and instructions to the patient and the assistant was given with the area marked with laser hazard signs. Activated laser tip was touched on the desired margin of the site of incisional biopsy which was about $2 \mathrm{~mm}$ away from the edge of the lesion. The tip was moved in a continuous motion and was not allowed to stop at a point for long to avoid charring of tissue [7]. The incision was deepened by continuously passing the laser tip in contact mode repeatedly over the margins. Once 
the desired depth was achieved the tissue was held with forceps and undermined to release the tissue. The site was checked for any bleeding and patient discharged once hemostasis was achieved (Figure 2).

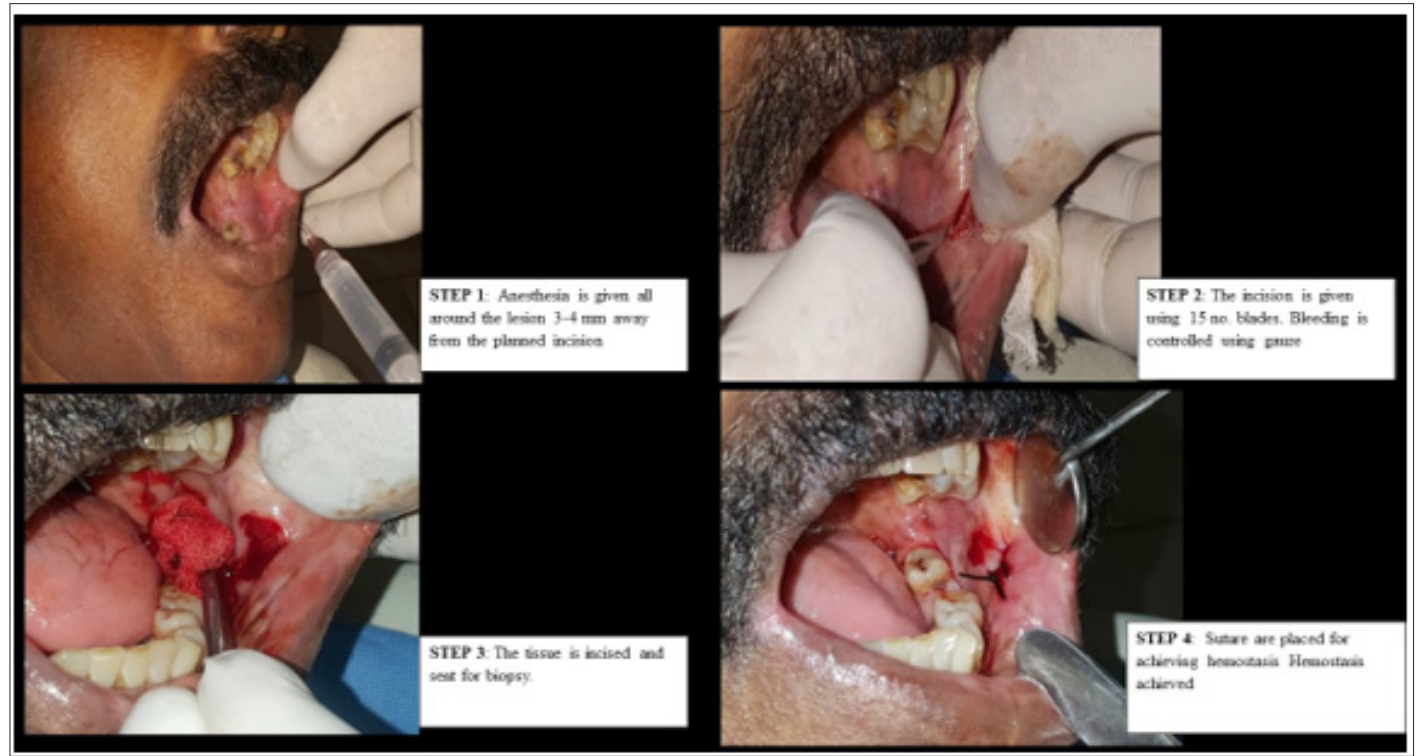

Figure 1: Steps in scalpel biopsy.

A. Step 1- after identifying the lesion local anesthesia with adrenaline is injected around the lesion 3-4mm away.

B. Step 2- incision given using a 15-no. blade and bleeding controlled with gauze.

C. Step 3- Tissue is excised and sent for biopsy.

D. Step 4- sutures are placed to achieve hemostasis.

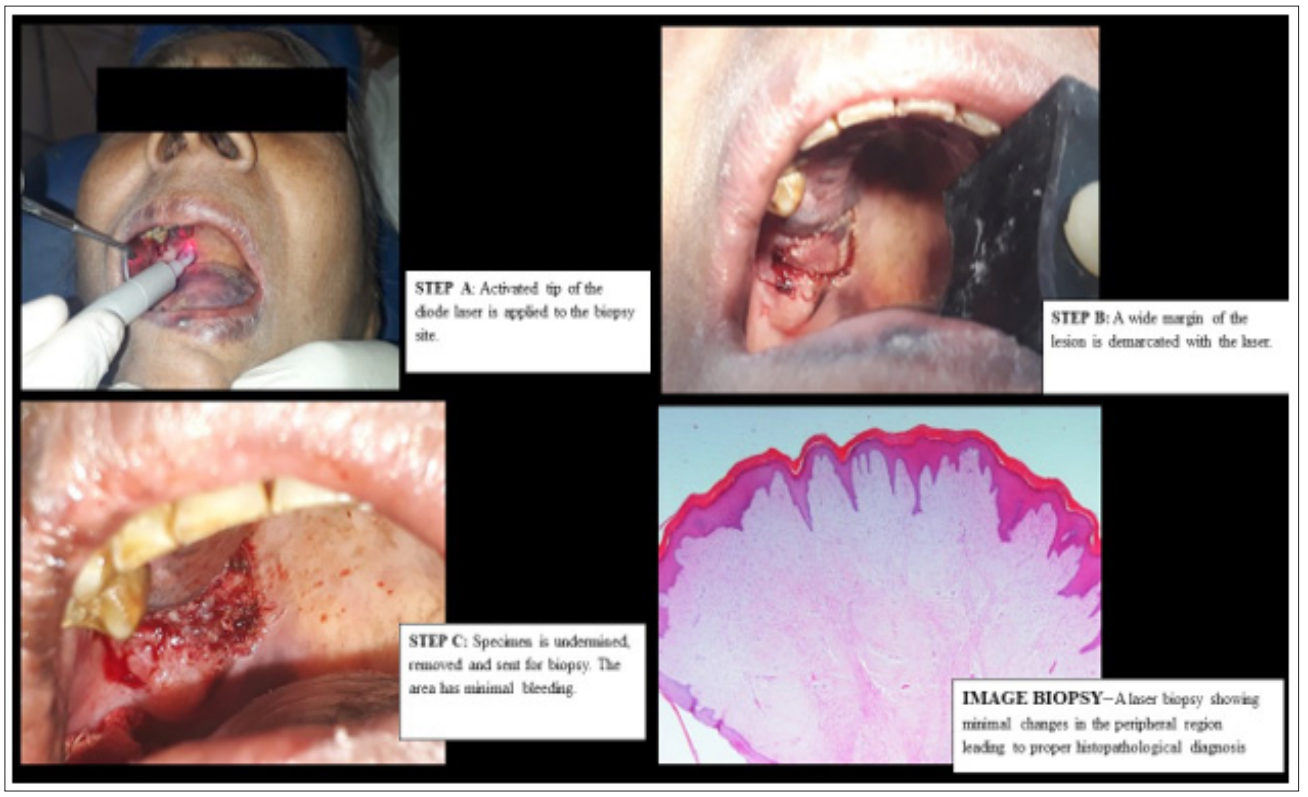

Figure 2: Image of biopsy-Biopsy showing minimal changes in the peripheral regions which leads to proper histopathological diagnosis.
A. Step A- Activated tip of the diode laser is applied to the biopsy site.
B. Step B- A wide margin of the lesion is demarcated with the laser.
C. Step C-Specimen is undermined and sent for biopsy. 


\section{Statistical analysis}

Data was analyzed by
A. Independent $t$ test
B. Chi square test of significance
C. Mann-Whitney u test
D. Wilcoxon signed-rank test

\section{Hemostasis}

Hemostasis was compared by measuring the change in weight of gauze pieces. In the scalpel group the mean change was $8.79+/$ $0.88 \mathrm{mg}$ while in laser the mean change was $0.94+/-0.34 \mathrm{mg}$ which was statistically significant (Table 1).

\section{Amount of local anesthesia}

The mean amount of local anesthesia administered in scalpel group was $2.97+/-0.76 \mathrm{ml}$ while the laser group the mean amount of local anesthesia administered was $0.91+/-0.44 \mathrm{ml}$ which was significantly less in the laser group (Table 1).

\section{Duration of the procedure}

In scalpel group the mean duration was $15.20+/-3.06 \mathrm{~min}$ while in laser group it was $15.10+/-4.13 \mathrm{~min}$. There was no statistically significant difference in duration of the procedure (Table 1).

\section{Pain on 1st and 3rd post-operative day based on VAS}

The patients were recalled on the $1^{\text {st }}$ and $3^{\text {rd }}$ post-operative day. The pain was recorded using a $10 \mathrm{~cm}$ VAS. In the scalpel group the mean pain on $1^{\text {st }}$ post-operative day was $6.90+/-0.96$ and on the $3^{\text {rd }}$ post-operative day was $2.77+/-0.57$. Mean change was $4.13+/-1.07$. In the laser group the mean pain on the $1^{\text {st }}$ day was $3.77+/-0.86$ and on the $3^{\text {rd }}$ day it was $1.53+/-0.57$. The mean change was $2.23+/-$ 1.01. When compared the pain in the laser group was significantly less statistically with significance being less than $p<0.005$. On the $3^{\text {rd }}$ post-operative day also the pain in the laser group was significantly less statistically than scalpel group. (Table 1).

Table 1: Summary of parameters recorded.

\begin{tabular}{|c|c|c|c|c|c|c|c|}
\hline \multirow{2}{*}{ Variables } & \multirow{2}{*}{ Time } & \multirow{2}{*}{ Groups } & \multirow{2}{*}{ Mean } & \multirow{2}{*}{ SD } & \multirow{2}{*}{ SE } & \multicolumn{2}{|c|}{ 95\% CI for Mean } \\
\hline & & & & & & Lower Bound & Upper Bound \\
\hline \multirow{6}{*}{ Pain } & \multirow{2}{*}{ Day 1} & Scalpel & 6.9 & 0.96 & 0.18 & 6.54 & 7.26 \\
\hline & & Laser & 3.77 & 0.86 & 0.16 & 3.45 & 4.09 \\
\hline & \multirow{2}{*}{ Day 3} & Scalpel & 2.77 & 0.57 & 0.1 & 2.55 & 2.98 \\
\hline & & Laser & 1.53 & 0.57 & 0.1 & 1.32 & 1.75 \\
\hline & \multirow{2}{*}{ Change } & Scalpel & 4.13 & 1.07 & 0.2 & 3.73 & 4.53 \\
\hline & & Laser & 2.23 & 1.01 & 0.18 & 1.86 & 2.61 \\
\hline \multirow{6}{*}{ Weight of gauze (in mg) } & \multirow{2}{*}{ Initial } & Scalpel & 4.91 & 0.82 & 0.15 & 4.61 & 5.22 \\
\hline & & Laser & 4.89 & 0.98 & 0.18 & 4.52 & 5.26 \\
\hline & \multirow{2}{*}{ Final } & Scalpel & 13.7 & 1.23 & 0.23 & 13.24 & 14.16 \\
\hline & & Laser & 5.82 & 1.02 & 0.19 & 5.44 & 6.2 \\
\hline & \multirow{2}{*}{ Changes } & Scalpel & 8.79 & 0.88 & 0.16 & 8.46 & 9.12 \\
\hline & & Laser & 0.94 & 0.34 & 0.06 & 0.81 & 1.06 \\
\hline \multirow{2}{*}{\multicolumn{2}{|c|}{ Duration of procedure (in minutes sec) }} & Scalpel & 15.2 & 3.06 & 0.56 & 14.06 & 16.34 \\
\hline & & 15.1 & 4.13 & 0.75 & 13.56 & 16.64 & \\
\hline \multirow{2}{*}{\multicolumn{2}{|c|}{ Amount of local anesthesia (in ml) }} & Scalpel & 2.97 & 0.76 & 0.14 & 2.68 & 3.25 \\
\hline & & 0.91 & 0.44 & 0.08 & 0.74 & 1.07 & \\
\hline
\end{tabular}

\section{Discussion}

The principal aim of obtaining a biopsy is to provide a specimen for histopathologic diagnosis of lesions. They can be indicated for any significant changes that have happened in any of the tissues in the oral or extra oral area [1].

A biopsy can be performed by a General Dentist or Oral Surgeon depending on the areas involved. The armamentarium needed for it similar to an oral surgical procedure like Mouth
Mirror, Probes, Explorer, Surgical Scalpel, Hemostats, Sutures, Local Anesthetic agents and Dissecting Scissors. The Anesthesia with a vasoconstrictor is not given into the lesion to prevent its distortion but at a distance about $3-4 \mathrm{~mm}$ away from the lesions margins so as to provide local loss of sensation and vasoconstriction which helps in getting a bloodless field. The specimen should be held with a toothless tissue holding forceps to avoid distortion of the architecture to the tissue, marked (anterior, posterior, superior and inferior margins), fixed and sent for evaluation. 


\section{Laser}

Laser is an acronym for "light amplification by stimulated emission of radiation" and was first demonstrated by Maiman in 1960. Light is a form of electromagnetic wave.

It works in either Contact mode (the distal end of the laser optic fiber is placed in direct contact of the target tissue) or Non-contact mode (the hand piece is held away from the tissue). Laser interacts with tissue by

A. Reflection: Beam redirects itself off the tissue surface without any effect on the target.

B. Absorption: The beam is absorbed by the target.

C. Transmission: The beam transmits through the tissue with no effect.

D. Scattering: The beam scatters on hitting the target [8].

Dental lasers use chromophores like hemoglobin, melanin, water and hydroxyapatite crystals with the Diode laser used in the present study $(980 \mathrm{~nm})$ the chromatophores are melanin, hemoglobin ( $\mathrm{Hb}$ ), and oxyhemoglobin. The oral cavity is a highly vascularized and pigmented the use of Diode laser offers significant advantages in cutting efficiency and getting a bloodless field [5,9]. Advantages of lasers for soft tissue cutting are that their use requires minimal or no anesthetic; they do not harm dental hard tissues; their judicious use does not injure the dental pulp; because of low or no heat production, they can be used around dental implants; they are antimicrobial, and they remove endotoxins from root surfaces [3,4].

The current study was done to compare the use of Diode laser (980nm, 3watt power in continuous mode) with scalpel in taking soft tissue incisional biopsy and to compare various parameters like pain, bleeding, duration of procedure etc. in relation to a normal scalpel biopsy [3]. Various studies that have been conducted using Diode lasers of different wavelengths like $940 \mathrm{~nm}, 1064 \mathrm{~nm}$ and $980 \mathrm{~nm}$. All the studies had concluded that at lower power setting the lasers had a distinct advantage over Surgical Scalpel in the areas of post-operative pain, Need of Local Anesthesia, achieving hemostasis and having a comparative blood less field $[3,4,10,11]$.

A few of the studies had evaluated the histopathological effects of various lasers at various power settings. The studies had concluded that at lower power settings the thermal damage is not that much so as to compromise the tissue. The $\mathrm{CO}_{2}$ Lasers had the least zone of thermal destruction while Diode lasers specially had maximum zone of thermal destruction of up to $1 \mathrm{~mm}$. This can be due to the fact that Chromatophores for Diode Lasers are melanin, hemoglobin ( $\mathrm{Hb}$ ), and oxyhemoglobin which are present abundantly in the oral cavity [7,11-13].

In the study the data was evaluated using Independent $t$ test, Chi square test of significance, Mann-Whitney u test and Wilcoxon signed-rank test. The study indicated that there was significant difference in blood loss, amount of anesthesia used, and postoperative pain. The parameters showed that the use of lasers is advantageous than a surgical scalpel. There was not much difference in duration of the procedure.

\section{Conclusion}

Injection, post-operative pain, bleeding, site of instruments going into and out of mouth are the biggest fear patient undergoing dental treatment has to face. A patient undergoing biopsy has to face the similar situation with fear stemming from injections, scalpel, bleeding and post-surgical pain. Dental laser is a versatile device which eliminates a lot of these problems. Lesser amount of anesthesia means less number of injections and reduced postoperative pain helps to calm a patient who is under stress. Laser also helps a dentist by providing a relatively bloodless field and cauterized wound margins, and potentially lesser post-operative complications. Our study concludes that use of lasers in a dental setup is advantageous for both patient and a dentist and is a good adjuvant to Surgical Scalpel in the arsenal of a surgeon.

\section{References}

1. Bernstein ML (1978) Biopsy technique: the pathological consideration. J AM Dent Assoc 96(3): 438-443.

2. Zargaran M (2014) A Review of biopsy in dentistry: Principles, techniques, and considerations. J Dent Mater Tech 3(2): 47-54.

3. Shalawe WS, Ibrahim ZA, Sulaiman AD (2012) Clinical comparison between diode laser and scalpel incisions in oral soft tissue biopsy. Al Rafidain Dent J 12(2): 337-343.

4. Munisekhar MS, Reddy KM, Ahmed SA, Suri C, Priyadarshini E (2011) Conventional scalpel vs laser biopsy: A comparative pilot study. Intl J Laser Dentistry 1(1): 41-44.

5. Pang P, Andreana S, Aoki A, Coluzzi D, Obeidi A, et al. (2010) Laser energy in oral soft tissue application. J laser Dent 18(3): 123-131.

6. Ramírez AM, Silvestre FJ, Simó JM (2007) Oral biopsy in dental practice. Med Oral Patol Oral Cir Bucal 12(7): E504-510.

7. Romeo U, Vecchi AD, Ripari F, Palaia G, Chippafreddo C, et al. (2007) Effects of different laser devices on oral soft tissues: in vitro experience. J Oral Laser applications 7(3): 155-159.

8. Johar K (2011) Fundamentals of laser Dentistry. ( $5^{\text {th }}$ edn), Jaypee brothers' Medical publishers (P) Ltd, New Delhi, India, pp. 1-20,105-120.

9. Rizoiu MI, Eversole LR, Kimmel AI (1996) Effects of erbium, chromium: yittrium, gallium, garnet laser on mucocutaneous soft tissue. Oral surg Oral med Oral pathol Oral Radiol Endod 82(4): 386-395.

10. Romanos G, Nentwig GH (1999) Diode Laser (980nm) in oral and maxillofacial surgical procedures: clinical observations based on clinical applications. J Clin Laser Med Surg 17(5): 193-197.

11. Derikvand N, Chinipardaz Z, Ghasemi S, Chiniforush N (2016) The versatility of $980 \mathrm{~nm}$ diode laser in dentistry: A case series. J Lasers Med Sci 7(3): 205-208.

12. Goharkhay K, Moritz A, Smith PW, Schoop U, Kluger W, et al. (1999) Effects on oral soft tissue produced by a diode laser in vitro. Lasers Surg Med 25(5): 401-406.

13. Suter VGA, Altermatt HJ, Sendi P, Mettraux G, Bornstein MM (2010) $\mathrm{CO}_{2}$ and diode laser for excisional biopsies of oral mucosal lesions. Schweiz Monatsschr Zahnmed 120(8): 664-671. 